\title{
Follow-up Investigation on the Transformation of Scientific and Technological Achievements of Jilin Province National Plan Project
}

\author{
Jing Liwei ${ }^{1}$, Wang Guihua ${ }^{1}$, Liu Jingyan ${ }^{1}$, Zhang $\mathrm{Ke}^{1}$, Zhang Bo ${ }^{3}$, Guo Mohan ${ }^{1}$, Chang Haiyan ${ }^{4}$, Li Yang ${ }^{2 *}$ \\ Jilin Province Science and Technology Information Institute, Changchun, Jilin130033 \\ Jilin University of Finance and Economics, Changchun, Jilin130117 \\ Jilin Province Science and Technology Fund Operation Service Center,Changchun, Jilin 130000 \\ Changchun Guanghua University, Changchun, Jilin 130000
}

\begin{abstract}
The National Science and Technology Plan Projects carry out the public interest and objectives of country in the aspects of scientific and technological innovation. Therefore, the concern for such projects is increasing day by day, but from the actual situation, the effect of project implementation results conversion and application is still not satisfactory. This paper adopts the method of research and analysis to collate and analyze the completion table of the national plan project to make followup investigation, sum up the characteristics of national science and technology plan achievements and the problems in the process of achieving transformation, and provide relevant suggestions for promoting the transformation and industrialization of scientific and technological achievements in Jilin province.
\end{abstract}

Keywords-National Science and Technology Plan Project; Transformation of Scientific and Technological Achievements; Follow-up Investigation; Problems

\section{INTRODUCTION}

The National Science and Technology Plan is an important part of the national science and technology activities. It is an important way and means to implement the national science and technology development plan, guide the scientific and technological activities and allocate the scientific and technological resources [1]. The National Science and Technology Plan Project Survey is a regular annual statistical survey organized and implemented by the Ministry of Science and Technology. Before 2014, this survey has always included two parts: Firstly, it is the survey on the implementation of the National Science and Technology Plan Project started in 1994; Secondly, it is the follow-up survey of the National Science and Technology Plan Project started in 2006. Due to the national system reform in 2015 , statistical surveys have only conducted follow-up investigation on the state-level science and technology plan projects since the year of 2014 .

In 2016, the National Science and Technology Plan Projects carry out follow-up investigation of 14 national science and technology major projects, 21 of the 863 program projects, 26 national science and technology support program projects, 25 of the 973 program projects, and 11 national major scientific research projects [2], a total of 97 projects. The contents of the follow-up investigation mainly include the output and adoption of achievements, transformation and application of achievements, the promotion and industrialization of achievements, the benefits and impacts generated, patents protection, etc.

\section{CharaCteristics OF NATIONAL Plan ProjeCT FOLLOWING UP AND INVESTIGATING THE SCIENTIFIC AND TECHNOLOGICAL ACHIEVEMENTS}

\section{A. There are various output forms of scientific and technological achievements}

The National Science and Technology Plan Projects have produced a number of scientific and technological achievements, including basic research, technical and platformbased achievements. After specific calculation: The core achievements of $46.86 \%$ of the researches are the intellectual achievements, including papers, books, research (consultation) reports, patents, etc.; The core achievements of $35.56 \%$ of the researches are the innovative technological achievements, including new products/ new varieties/ new materials, new technologies/ new processes, as well as new equipment/ new instruments; The core achievements of $17.58 \%$ of the researches are the establishment of prototypes, demonstration projects, and technical support platforms (databases, technology research and development/promotion platform). The following is a concrete analysis of the achievements output according to the project undertaking unit and subject type:

According to the nature of the project undertaking unit, the core achievements of the projects undertaken by institutions of higher learning and scientific research institutes are similar, which are mainly the thesis works, research reports, patents, and technical achievements. The projects led by the enterprise pay great attention to the technical achievements. Nearly $7 \%$ of the projects set new products, new processes, prototypes and various technological achievements as the main core achievements, followed by patents, paper works, research reports, demonstration projects or technology support platforms. 


\section{According to the subject type:}

(1)The 973 Program focuses on basic research and scientific exploration. Among the 25 subjects, the core achievements are thesis, writings, research reports and patents, accounting for $64.71 \%$, followed by patents, new technologies and new processes, accounting for $13.73 \%$. New products, standards, prototypes, the establishment of demonstration projects or technical support platforms that set application as the core achievements account for $21.56 \%$.

(2)Among 21 subjects of the 863 Program, the top core achievements are papers, books, research (consultation) reports, patents, new technologies, and new processes, accounting for $55.36 \%$; The second is the new products, new devices and prototypes, accounting for $35.71 \%$; those that set the establishment of demonstration projects or standards as the core achievements account for $8.93 \%$.

(3)Those that set the supporting subjects, new technologies, new processes and other achievements as the most important core achievements account for $57.75 \%$ of such types of achievements among the 26 subjects; the core achievements of $33.80 \%$ of the subjects are demonstration projects, new products, new devices and new instruments; those that set the prototypes, technical support platforms and computer software achievements as the core achievements account for $8.45 \%$.

(4)National major scientific research programs and national science and technology major projects set the papers, works, research (consultation) reports and patents as the core achievements, which accounts for $52.54 \%$; the next is the new products and new processes, accounting for $30.51 \%$; those that set the establishment of demonstration projects, technical support platforms and standards as the core achievements account for $16.95 \%$.

\section{B. The research achievements of the National Science and Technology Plan Project better serve many areas of social and economic service fields}

The research achievements of various kinds of national plan projects have been applied or served in a wide range of fields, which have effectively supported the economic and social development and the construction of ecological civilization. From the socio-economic objectives of the application or service of the research achievements of the subjects, the research achievements of the 863 program are mainly concentrated in the fields of energy production, distribution and rational utilization, accounting for $37.5 \%$ of this target area. The research achievements of the supporting projects are mainly concentrated in the field of agriculture, forestry, animal husbandry and fishery, accounting for $33.3 \%$ of this target area. The achievements of the 973 program are mainly concerned with the exploration of natural phenomena, and the research achievements belonging to this target area account for $36 \%$. The focus of major scientific research project achievements is on environmental protection, ecological construction, pollution prevention and other non-directional research. The most important area for the application of science and technology major project achievements is in the development of health services, accounting for $46.67 \%$ of this area

\section{The research achievements of the National Science and Technology Plan Project effectively promote products entering the market}

The ability for the research achievements to form product gets constantly improved, and the market subject status gradually becomes prominent. The survey results show that after 1-3 years of promotion and transformation of the research achievements, the product market of a considerable portion of the achievements has undergone a good transformation. In 2016, the proportion of non-formed products decreased by $2.5 \%$ and the proportion of non-marketed products decreased by $7.5 \%$ compared to the time when the project was completed. In larger markets and smaller market, the shares have increased by $5.0 \%$. In other words, the achievements shifting to $55.0 \%$ by 2016 will be brought to market and form a certain market share 

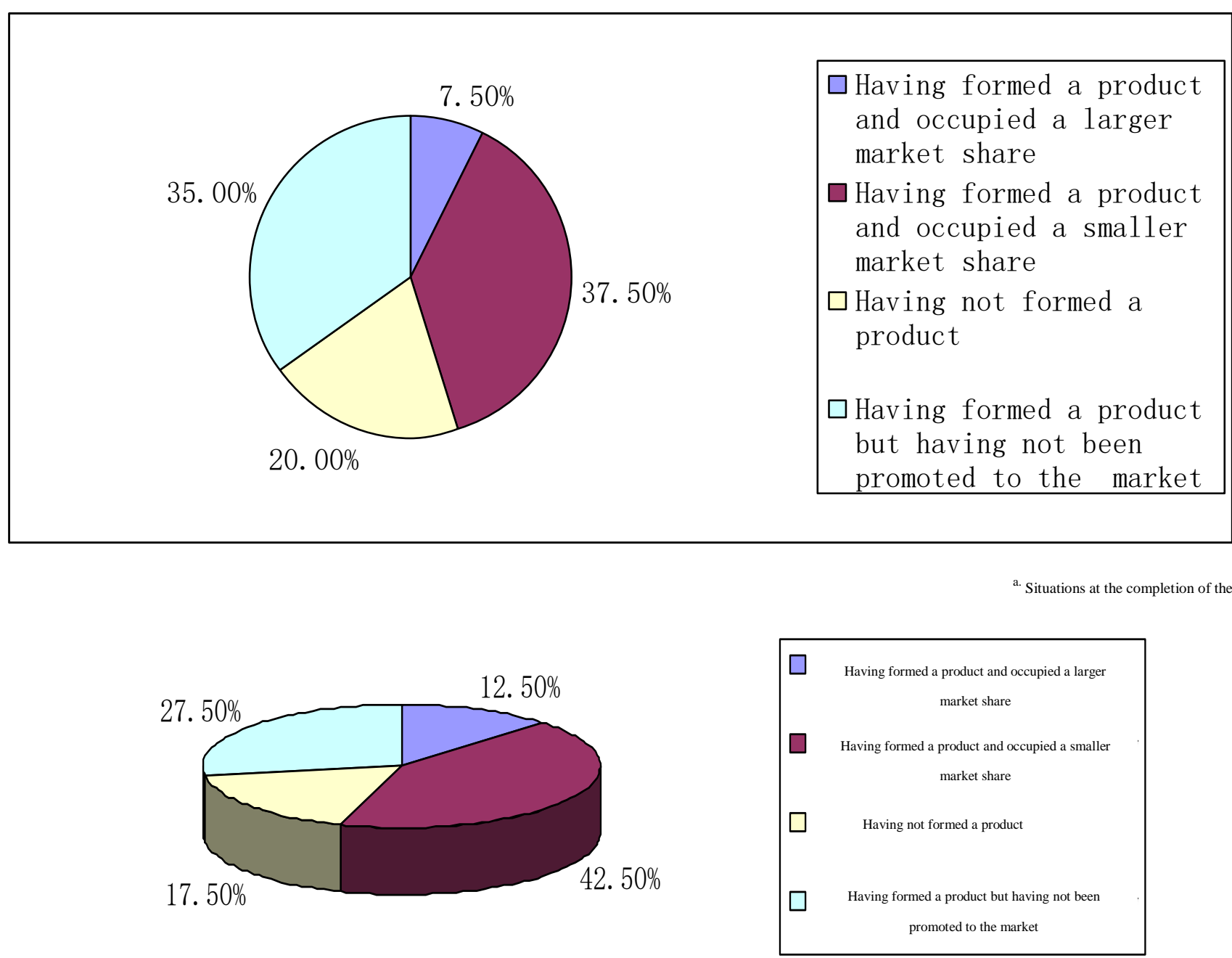

Fig. 1 The percentage of products forming and entering the market

Comparing with the achievements of various units, it can be seen that the proportion of productization and marketization of achievements has greatly improved. In 2016, the proportion of the enterprises' achievements entering the market was the highest in the market, reaching $41.17 \%$; $25 \%$ of the achievements of the institutions of higher learning have entered the market, and the proportion has increased by $2.5 \%$ compared to the time when the project was completed; $20 \%$ of the achievements of the scientific research institutions have entered the market, and the proportion has increased by $5 \%$ compared to the time when the project was completed;

\section{PROBLEMS ENCOUNTERED IN THE TRANSFORMATION AND TRANSFER PROCESS OF RESEARCH ACHIEVEMENTS OF THE NATIONAL PLAN PROJECT}

A. The transformation and transfer ratio of research achievements of the National Plan Project is low

By the end of 2016, the research achievements transformed/applied projects have achieved good social and ecological benefits. It has accumulatively reduced the emission of waste gas for $1,170,000$ cubic meters, the waste water for 335,000 tons, and the waste for 290,000 tons, and saved the electricity, coal, oil, and gas which are converted to coal for 2,001,000 tons. However, the research achievements have been transformed and transferred at a lower proportion, and of the 97 subjects that have been carried out the follow-up investigation, only the achievements of 40 subjects have got transformed/applied, accounting for $41.24 \%$ and less than $50 \%$ of the total. 
B. According to the categories of plan projects and leading units, there is a large gap between different subjects

The benefits of the project achievements after transformation are mainly derived from the transformation of the achievements of the support plan and national science and technology major projects, and $70.6 \%$ of the newly increased output value and $100 \%$ of the export value come from the subjects led by the enterprise. There is a significant difference in the transformation of the achievements for different types of projects and project undertaking units. The details are as follows:

(1)The supporting plan is oriented towards the economic construction, focuses on solving the common problems of the industry, and carries out key technical tackling and demonstration. Of the 26 supporting subjects that have been carried out the follow-up investigation, only the achievements of $65.38 \%$ subjects have got transformed / applied. Of the 14 major science and technology special projects, the achievements of $57.14 \%$ subjects have got transformed /applied. Of the 21863 program projects, the achievements of $47.62 \%$ subjects have got transformed /applied. The purpose of the 973 program is to support the basic research, with the aim of exploring the natural law and increasing the cognition of objective things. Among the 25 subjects, the achievements of only $20 \%$ of the subjects have been transformed/ applied. Among the national major scientific research programs, 11 subjects have not been transformed/ applied.

(2)For the subjects led and undertaken by different types of units, there is a big difference in the transformation/application proportion of their achievements. The proportion of the subject transformation/applications led by the enterprise reached $88.24 \%$, which was higher than that of research institutes $(32.50 \%)$ and institutes of higher learning (30.00\%).

\section{The combination of enterprise, university, and institute is not close in the process of the transformation of National Plan Project research achievements}

From the perspective of the transformation and application ways of the research achievements, most of the transformation/applications are by self-investment, accounting for $26.74 \%$; The second is to make use of the achievements to provide technical services (consultation), accounting for $17.44 \%$; Those using the achievements as a condition of cooperation to jointly implement transformation with others rank in the third place, accounting for $16.28 \%$; Then those that permit others to use the scientific and technological achievements account for $12.79 \%$. Among the 40 973, 863, supporting, national major scientific research plan and national science and technology major special projects whose achievements have got transformed/applied, only 8 subjects have obtained the transformation income through the transfer of the achievements. The transformation income obtained is mainly derived from the following aspects: 1 . Transfer achievements: RMB 21,020,000; 2.Direct income from cotransformation: RMB 6,000,000.
The most important way of transforming the achievements of the subjects led by the enterprise is to implement selfinvestment for transformation, which accounts for $59.09 \%$. The main way of transforming/applying the achievements of the subjects led by the institutes of higher learning is to implement self-investment for transformation, permit others to use the scientific and technological achievements, and use the achievements as a condition of cooperation to jointly implement the transformation with others. The three methods of transformation account for $18.92 \%$; the next is to provide technical services and transfer the technology/patent to the external with the achievements, which accounts for $13.51 \%$ and $10.81 \%$ respectively. The research institutes mainly use the achievements to provide technical services to the external, which accounts for $29.63 \%$. Next, it is the use of the achievements as a condition of cooperation to jointly implement transformation with others and make it used in public welfare promotion and application, which account for $18.52 \%$ and $14.81 \%$ respectively.

\section{The self-use proportion of project achievements is excessive, and proliferation proportion needs to be strengthened}

The users of the achievements are single. $87.5 \%$ of the users who take the lead in the subjects are the participating units of the enterprise or the subject, namely, they are mainly for the self-use of the participating research and development units. Only $6.25 \%$ of the users belong to the units and other users external to the projects. For the subjects led by the scientific research institutes and institutions of higher learning, and the main users of the achievements are also the participating units of the subjects, accounting for $36.36 \%$ and $40.74 \%$ respectively.

\section{REASONS WhY RESEARCH ACHIEVEMENTS HAVE NOT BEEN TRANSFORMED/APPLIED}

\section{A. There are difficulties in investment and financing during the promotion or industrialization of research achievement}

Whether there are sufficient funds in the promotion or industrialization of the research achievements will affect the process and effectiveness of promotion and industrialization to a large extent. The investigation shows that $72 \%$ of the researches have met the financial difficulties. The researches that have sufficient and relatively sufficient industrialization funds account for 5\% and 7\% respectively, and those that have generally sufficient funds account for $16 \%$.

\section{B. The supply and demand docking system for achievements transformation needs to be established}

The above scientific and technological achievements are technologically advanced, but there are many problems encountered in the transformation process. Many scientific and technological achievements can be perfectly realized in the laboratory, but the transformation process of achievements is still not smooth due to certain distance between the forming of the product marketization process and the laboratory such as the high cost, the uncertain batch repeated production process, 
etc. In addition, in order to successfully transform the scientific and technological achievements, there is a need for a pilot link between laboratories and the specific production processes. However, as for who should be responsible for the pilot link and how much responsibility should be borne by the enterprises and the scientific and technological workers, there are great disagreements between the two sides and consensus cannot be reached, so that the transformation of achievements is hindered. [3]

\section{The ability of independent research and development as well as technological innovation of enterprise is not strong}

Whether scientific and technological achievements can be transformed into market-oriented products is closely related to their own value. In the present market environment, the scientific and technological achievements owned by the enterprises include the independent research and development, cooperative research and development, as well as introduction and purchases, while most of them belong to cooperative research and development or introduction and purchases. The enterprises are more concerned about the marketization as soon as possible, while ignore the previous research and development input and detailed market analysis, thus making the transformation of the basic or applied scientific research results unable to get market support. In addition, the enterprise's incentive to scientific research workers and the attribution of intellectual property rights have not yet been clarified, which has reduced the enthusiasm and initiative of the scientific researchers and seriously affected the transformation of scientific and technological achievements. [4]

\section{There is an urgent need to establish a policies and rules system for joint implementation of departments}

The transformation of scientific and technological achievements requires policy support and correct policy guidance. At the same time, the government's regulatory department is the leader and manager of the industrialization of scientific and technological achievements in colleges and universities. In recent years, many documents have been introduced in our province in the field of scientific and technological achievements[5],such as Provisional Measures for Jilin Province to Motivate Scientific Researchers to Accelerate the Transformation of Scientific and Technological Achievements, Some Regulations on Jilin Province's Promotion of Transformation of Equity in Scientific and Technological Achievements and Dividends, etc. However, these policy documents are generally formulated by one department or a few departments jointly and other departments are not aware of the above policy documents. Therefore, the operability of documents is limited by a certain amount, and many policies are not implemented in place.

\section{E. Intermediary service system is not perfect, and the information of supplier and demander is asymmetric}

In the process of the transformation of scientific and technological achievements, the intermediary service institution has set up a good communication platform for both the supplier and demander. However, due to the lack of clear and independent legal status of the service body of the intermediary institutions in our country, the development of the intermediary market is not perfect, the professional level of the staff is not high, the service quality is low, and the service team level is uneven, which makes the intermediary market continue to languish, and the sale information of science and technology knowledge products cannot be completely symmetrical. [6]

\section{CONCLUSION}

Based on the previous research and analysis, this paper points out many achievements made by our country's national science and technology plan projects: the output of scientific and technological achievements is large and the achievements better serve for many social and economic service fields, which has effectively promoted the product to enter the market; However, there are some problems in the process of transformation and industrialization. For example, there are difficulties in investment and financing at the promotion or industrialization stage of the research achievements, the ability of independent research and development and technological innovation of the enterprise is not strong, and the proliferation proportion of the research achievements needs to be strengthened. Different from the previous reports, this paper has made a specific analysis of the problems encountered in the transformation process of the scientific and technological achievements of the government investment subjects. The ways to solve the problems are to: improve the innovation ability of the project undertaking unit, set up an innovation platform for the transformation of scientific and technological achievements, encourage joint research and development of government, enterprise, university, institute and business, formulate preferential policies and other ways to improve the level and ability of achievements transformation and industrialization.

\section{ACKNOWLEDGMENT}

Fund Project: this paper belongs to the national science and technology statistic project NSTS-2016-15 "Evaluation and Analysis Research of Innovation Ability of Scientific Research Institutions-Taking Jilin Province as an Example".

Profile of the Author: Jing Liwei (1982- ), female, born in Harbin, Heilongjiang Province, Associate Researcher of Jilin Province Science and Technology Information Institute. Li Yang (1980-), female, born in Changchun, Jilin Province, Associate Professor of Jilin University of Finance and Economics, School of Accounting 


\section{REFERENCES}

[1] Li Yan. An Analysis of the Main Features of the National Science and Technology Plan Projects Undertaken by Guangdong Province. Guangdong Science and Technology, 2016, 25(15): 68-70.

[2] Fan Hongmei. The Investigation and Analysis of the National Science and Technology Plan Projects Undertaken by Gansu Province in 2013. Gansu Science and Technology, 2014, 30 (24): 4-7.

[3] Zhang Yaxin. Problems and Countermeasures Construction in the Transformation of Scientific and Technological Achievements in Our Country. Heilongjiang Textile, Issue 1, 2006.

[4] Hu Xiaoxue. The Promotion Strategy Analysis of the Transformation Efficiency of Scientific and Technological Achievements. Academic Research, Issue 17, 2016.

[5] Bi Mingxiong. Property Right Issues and Model Selection in the Marketization of Technological Achievements, Focus, 2017(07):000106.

[6] Shi Tong, Wang Chunxi, \&Tan Wenjun. Current Problems and Countermeasures in the Transformation of Scientific and Technological Achievements, Productivity Research, Issue 6, 2017. 